Orbis Tertius, vol. XXIV, $\mathrm{n}^{\circ}$ 30, e141, noviembre 2019-abril 2020. ISSN 1851-7811

Universidad Nacional de La Plata

Facultad de Humanidades y Ciencias de la Educación

Centro de Estudios daTeoría y Crítica Literaria

\title{
Ofelia Ros, Lo siniestro se sigue riendo en la literatura de Lamborghini, Aira y Carrera, y en la produccion cultural poscrisis 2001. Pittsburgh, Universidad de Pittsburgh, 2016, Nuevo Siglo, 208 páginas
}

Lo siniestro se sigue riendo en la literatura de Lamborghini, Aira y Carrera, y en la producción cultural poscrisis 2001 de Ofelia Ros es una contribución lúcida en el campo de la crítica literaria argentina contemporánea. La lectura atenta de los escritores Osvaldo Lamborghini, César Aira, Arturo Carrera y Washington Cucurto, como también la producción editorial de Eloísa Cartonera, le permite identificar un residuo, basura y o desperdicio inquietante, siniestro y familiar como producción cultural correspondiente a la lógica del capital.

En la Introducción al libro, Ros traza su recorrido con la meta de "poner en cuestión no únicamente los rasgos de una clase social, sino la miseria de toda una época: una causalidad, una dialéctica propia que va de subjetividad a subjetividad, y escapa cualquier condicionamiento individual" (p. 8). Tal vez que "la miseria de toda una época" sea un abuso retórico, pero se podría decir que este libro logra señalar la contradicción yacente en la modernidad argentina; es decir, se trasluce el deseo de una cultura propia que solo encuentra posibilidad de existencia en su desvanecerse del mercado globalizado. La escritura de Aira, Lamborghini, Carrera y Cucurto, con la editorial Eloísa Cartonera, le permite identificar ese malestar en la producción cultural a través del humor negro, la parodia y el sinsentido leído en estos autores. Apoyándose en cierta tradición filosófica y política continental (como Lukács, Lacan, Žižek, Rancière, Derrida y, por supuesto, Freud), Ros propone como eje articulador el concepto freudiano de "lo ominoso". Por lo que tal "malestar", aunque la autora no lo identifica como tal, se proyecta sobre una noción de Inconsciente que tendría vía regia de acceso a través del componente "ominoso" de sus escrituras, dado que "[todo] lo que estando destinado a permanecer en lo secreto, en lo oculto, ha salido a la luz" (Freud, 1917, p. 220) en el humor negro, la parodia y el sinsentido.

El artículo freudiano Lo ominoso le da marco teórico a su lectura, por lo que cada uno de los capítulos se hará cargo de algún elemento identificado en la noción esbozada de "ominoso". El primer capítulo entonces, aborda la escritura de César Aira acuñando la noción de "idea siniestra”; el segundo capítulo, sobre Osvaldo Lamborghini, le da ingreso a la "risa" que se desprendería del sentido del humor. Esta risa es señal, o válvula de escape, de una tensión fuera de lugar y a destiempo en los discursos racionales. El tercer capítulo aborda el dinero como eje de la relación siniestra en la que éste perpetúa su condición de sublime a través del (re)conocimiento de su lugar en la cultura. El poemario Potlatch de Arturo Carrera articula un lado del prisma que se construye sobre la subjetividad sujetada a la lógica del capital. En el último capítulo, Ros aborda directamente esta extrañeza-familiar del dinero en su condición de crisis económica. En este capítulo se privilegia la contingencia de la crisis como paradigma por el cual, en el vaivén de lo visible e invisible, lo siniestro hace su apariencia: la miseria de una época.

Tal vez que el epígrafe del último capítulo, el conocido aforismo lacaniano de referencia a Hegel, "[mejor] pues que renuncie quien no pueda unir a su horizonte la subjetividad de su época” (p. 153), resuma el 
trasfondo de la propuesta de lectura: señalar la violencia y sumisión a la lógica capitalista de una época. Paradojalmente, para ese sujeto que no renuncia y une su subjetividad a la de su época, la basura, el desperdicio, el resto de lo consumado, es la vía y posibilidad de retorno al mercado neoliberal. La sonrisa, o el chiste, resguarda esa posibilidad de retorno. La "extrañeza inquietante", dice la autora, "abre un espacio para una demanda de participación insistente y perturbadora, comúnmente ignorada o negada" (p. 156). Es por esto que las "expresiones culturales de la poscrisis requieren de un cambio en las maneras de percibir, juzgar y actuar ante el desempleo, el dinero, la pobreza y la cultura" (p. 156). Este requerimiento, sin embargo, parece más un ejercicio de adaptación creativa al medio, donde lo ominoso resguarda esa posibilidad activa, que una apertura a una política otra. El lector, en este punto, se preguntaría por la posibilidad del fin de su época, y si los proyectos editoriales se resguardan algo más, en esa extrañeza inquietante, que tan solo el retorno de una subjetividad a la lógica capitalista. Desde esta perspectiva, Ros plantea una visión de la crisis económica en la que lo ominoso es índice del horizonte cerrado de una época. Es decir, la partición de los espacios ya está diseñada desde ese horizonte o, en otras palabras, está comprendida entre los límites de la subjetividad moderna. No obstante, sería importante no olvidar que el elemento familiar de lo ominoso es en su relación con la no correspondencia del hogar, por lo tanto, con lo abierto de ese horizonte de la subjetividad.

Desde el título del libro, Ros exige un lector perspicaz y paciente dispuesto a dejarse llevar por su propuesta. Si bien el concepto freudiano de lo siniestro ya se articula en él como tesis a ser desarrollada, la posición teórica psicoanalítica se complejiza al incorporar el análisis político y económico. De ahí que la miseria de una época es abordada desde lo visible del sufrimiento gozoso que se presenta en su condición ominosa, "a medias" diría Lacan, en la literatura argentina. Pero también, el título anuncia que su lector debe estar familiarizado con la producción cultural regional dada la ausencia de referencia geopolítica; por ejemplo ¿se trata de Leopoldo u Osvaldo Lamborghini? El "se sigue riendo" también marca la predominancia del sentido freudiano - en un "se reía antes" y en un "continúa haciéndolo ahora" - sobre la literatura, por lo que se sobreentiende que los autores sugeridos serán puestos a prueba del lente psicoanalítico.

Lo siniestro se sigue riendo en la literatura de Lamborghini, Aira y Carrera, y en la producción cultural poscrisis 2001 es una reflexión sofisticada y compleja que invita al lector a cuestionarse sobre los límites de la subjetividad y sobre el horizonte de una época y sus (im) posibles puntos de fuga de la mirada moderna.

Marcelino Viera

\section{REFERENCIAS BIBLIOGRÁFICAS}

Freud, S. (1917). De la historia de una neurosis infantil. Obras completas XVII. Buenos Aires, Argentina: Amorrortu. 